\title{
Surfactant apoprotein-A concentration in airway secretions for the detection of pulmonary oedema
}

\author{
S. Shimura, T. Masuda, T. Takishima, K. Shirato
}

\begin{abstract}
Surfactant apoprotein-A concentration in airway secretions for the detection of pulmonary oedema. S. Shimura, T. Masuda, T. Takishima, K. Shirato. (OERS Journals Ltd 1996.

ABSTRACT: Patients with cardiogenic pulmonary oedema expectorate foamy sputum containing surfactant, which might be expected to include surfactant apoprotein A (SP-A). SP-A is specific for lung surfactant. We have measured the SP-A concentration in airway secretions to determine whether it is useful in distinguishing pulmonary oedema from other disorders.

Samples of sputum and of aspirated airway secretion were obtained from 11 patients with cardiogenic pulmonary oedema, seven patients with clinically stable congestive heart failure, five patients with adult respiratory distress syndrome (ARDS) and 20 control patients (10 intubated) with other respiratory diseases. The samples were used for the measurement of SP-A concentration by a two-site simultaneous immunoassay with monoclonal antibodies against SP-A.

SP-A concentrations, measured in samples of sputum and aspirated secretions, depended on the diagnosis of the patients from which they had come. In descending order these samples came from patients with: cardiogenic pulmonary oedema $\left(1324 \pm 197 \mu \mathrm{g} \cdot \mathrm{mL}^{-1} ; \mathrm{n}=33\right)$; ARDS $\left(311 \pm 47 \mu \mathrm{g} \cdot \mathrm{mL}^{-1} ; \mathrm{n}=23\right)$; clinically stable congestive heart failure $\left(\mathbf{7 8} \pm 10 \mu \mathrm{g} \cdot \mathrm{mL}^{-1} ; \mathrm{n}=\mathbf{2 1}\right)$; and control conditions $\left(3.0 \pm 0.6 \mu \mathrm{g} \cdot \mathrm{mL}^{-1}\right.$; $\mathrm{n}=30$ ). Concentrations from disease samples did not overlap with controls. In samples from patients with cardiogenic pulmonary oedema, the SP-A concentration correlated with mean pulmonary capillary wedge pressure (PCWP) $(p<0.001 ; n=39)$.

These findings indicate that the measurement of the surfactant apoprotein $A$ concentration in airway secretions may be useful for the detection of pulmonary oedema.
\end{abstract}

Eur Respir J., 1996, 9, 2525-2530.
First Department of Internal Medicine, Tohoku University School of Medicine, Sendai 980-77, Japan.

\section{Correspondence: S. Shimura}

First Department of Internal Medicine Tohoku University School of Medicine 1-1 Seiryo-machi

Aoba-ku

Sendai $980-77$

Japan

Keywords: Airway secretion pulmonary oedema sputum

surfactant apoprotein A

Received: March 141996

Accepted after revision August 251996
Patients with cardiogenic pulmonary oedema expectorate foamy sputum, which might be expected to contain large amounts of surfactant. The pulmonary surfactantassociated $35 \mathrm{kDa}$ protein, surfactant apoprotein A (SPA), is the predominant phospholipid-associated glycoprotein in pulmonary surfactant, and is specific to lung surfactant [1]. Since, in the alveoli, SP-A is turned over rapidly ( $\leq 2 \mathrm{~h})$ [2], it is possible that the amount of SP$\mathrm{A}$ in airway secretions reflects pulmonary oedema. Monoclonal antibodies prepared against SP-A [3] have been used to measure the surfactant concentration in amniotic fluid for the diagnosis of infantile respiratory distress syndrome, and in sputum for the diagnosis of pulmonary proteinosis [4-8].

Meanwhile, clinical and radiographic methods for detecting congestive heart failure or pulmonary oedema are sometimes insensitive and have limited reliability [9]. The pulmonary capillary wedge pressure (PCWP) is an important indicator of cardiac function in patients with congestive left heart failure. Haemodynamic monitoring of this pressure using a balloon-tipped, flow-directed catheter [10] has, therefore, become commonplace in acutely ill patients. Because it is an invasive procedure and occasionally causes serious complications [11], however, pulmonary artery catheterization may not be an acceptable alternative either for screening or the initial detection of congestive heart failure or cardiogenic pulmonary oedema. Furthermore, in noncardiogenic pulmonary oedema or adult respiratory distress syndrome (ARDS), the PCWP is low or normal and does not reflect the extent of pulmonary oedema. In the present study, using monoclonal antibodies against SP-A, we measured the SP-A concentration in samples of airway secretions aspirated from intubated patients and sputum from patients with pulmonary oedema, in order to determine whether it may be used to detect pulmonary oedema.

\section{Methods}

\section{Subjects}

In the 6 yrs from 1989 until 1994, we investigated 11 patients with cardiogenic pulmonary oedema (4 females and 7 males, aged $67 \pm 4$ yrs (mean \pm SE)), who were admitted to the intensive care unit (ICU) at Tohoku University 
Hospital and selected for the present study, as shown in table 1. All were monitored for PCWP for 2-7 days. Diagnosis of cardiogenic pulmonary oedema was based on elevated mean PCWP $(\geq 12 \mathrm{mmHg})$, presence of heart failure due to heart disease and diffuse infiltrates on chest radiographic image. Six patients with cardiogenic pulmonary oedema received tracheal intubation with mechanical ventilation (table 1) and showed significant intratracheal secretions. Airway secretions aspirated without the addition of fluid, and sputum samples (1-5 mL) were then collected from these patients on successive morning.

Table 1. - Subjects

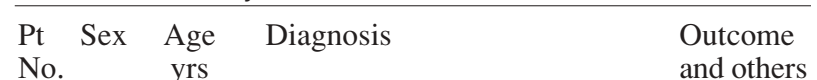

\section{Cardiogenic pulmonary oedema}

\begin{tabular}{|c|c|c|c|c|}
\hline 1 & $\mathrm{~F}$ & 60 & $\begin{array}{l}\text { Old myocardial infarction, } \\
\text { congestive heart failure }\end{array}$ & \\
\hline 2 & M & 79 & $\begin{array}{l}\text { Aortic regurgitation, } \\
\text { old myocardial infarction, } \\
\text { congestive heart failure }\end{array}$ & \\
\hline 3 & M & 62 & $\begin{array}{l}\text { Old myocardial infarction, } \\
\text { atherosclerosis obliterans, } \\
\text { congestive heart failure }\end{array}$ & \\
\hline 4 & M & 64 & $\begin{array}{l}\text { Dilated cardiomyopathy } \\
\text { dead }\end{array}$ & Respirator, \\
\hline 5 & M & 69 & $\begin{array}{l}\text { Old myocardial infarction, } \\
\text { congestive heart failure }\end{array}$ & \\
\hline 6 & F & 42 & $\begin{array}{l}\text { Acute myocardial infarction, } \\
\text { diabetes mellitus }\end{array}$ & $\begin{array}{l}\text { Respirator, } \\
\text { dead }\end{array}$ \\
\hline 7 & M & 62 & Ischaemic heart disease, & Respirator, \\
\hline
\end{tabular}
unstable angina, congestive heart failure

$\begin{array}{rrrrr}8 & \mathrm{M} & 62 & \begin{array}{l}\text { Acute myocardial infarction } \\ \text { dead }\end{array} & \text { Respirator, } \\ 9 & \mathrm{~F} & 89 & \begin{array}{l}\text { Ischaemic heart disease, } \\ \text { congestive heart failure }\end{array} & \text { Respirator } \\ 10 & \mathrm{~F} & 76 & \begin{array}{l}\text { Ischaemic heart disease, } \\ \text { congestive heart failure }\end{array} & \text { Respirator } \\ & \text { M } & 73 & \begin{array}{l}\text { Ming } \\ 11\end{array} & \end{array}$

11 M 73 Mitral regurgitation, old pulmonary tuberculosis

Clinically stable congestive heart failure

\begin{tabular}{|c|c|c|c|c|}
\hline \\
\hline 12 & $\mathrm{M}$ & 79 & \multirow{2}{*}{\multicolumn{2}{|c|}{$\begin{array}{l}\text { Old myocardial infarction } \\
\text { Old myocardial infarction, } \\
\text { ventricular aneurysm }\end{array}$}} \\
\hline 13 & $\mathrm{~F}$ & 79 & & \\
\hline 14 & $\mathrm{~F}$ & 55 & \multicolumn{2}{|l|}{$\begin{array}{l}\text { Mitral stenosis, } \\
\text { Ischaemic heart disease }\end{array}$} \\
\hline 15 & $\mathrm{~F}$ & 75 & \multicolumn{2}{|l|}{$\begin{array}{l}\text { Aortic stenosis, Mitral } \\
\text { regurgitation, pulmonary } \\
\text { hypertension }\end{array}$} \\
\hline 16 & M & 69 & \multicolumn{2}{|l|}{ Ischaemic heart disease } \\
\hline 17 & M & & \multicolumn{2}{|l|}{ Replacement of aortic aneurysm } \\
\hline 18 & M & & \multicolumn{2}{|l|}{ Aortic regurgitation } \\
\hline \multicolumn{5}{|c|}{ Adult respiratory distress syndrome } \\
\hline 19 & M & 67 & $\begin{array}{l}\text { Perforation of duodenal ulcer, } \\
\text { peritonitis, sepsis }\end{array}$ & $\begin{array}{l}\text { Respirator, } \\
\text { dead }\end{array}$ \\
\hline 20 & $\mathrm{~F}$ & 22 & $\begin{array}{l}\text { Rickettsia infectious disease } \\
\text { DIC }\end{array}$ & $\begin{array}{l}\text { Respirator, } \\
\text { dead }\end{array}$ \\
\hline 21 & M & 48 & $\begin{array}{l}\text { Lung abscess, sepsis, DIC, } \\
\text { diabetes mellitus }\end{array}$ & Respirator \\
\hline 22 & $\mathrm{~F}$ & 70 & $\begin{array}{l}\text { Lung abscess, sepsis, DIC } \\
\text { dead }\end{array}$ & Respirator, \\
\hline 23 & $\mathrm{~F}$ & 42 & Sepsis, DIC & $\begin{array}{l}\text { Respirator, } \\
\text { dead }\end{array}$ \\
\hline
\end{tabular}

DIC: disseminated intravascular coagulation; M: male; F: female.
In addition, seven clinically stable patients with chronic congestive heart failure ( 3 females and 4 males, aged $68 \pm 5 \mathrm{yrs}$ ), who had shown no evidence of acute pulmonary oedema for at least 3 months and who expectorated morning sputum, were chosen for the present study.

Five ARDS patients ( 3 females and 2 males, aged $50 \pm$ 9 yrs) were also studied. The definition of ARDS was based on the following criteria: presence of diffuse infiltrates involving all four lung quadrants in the anterioposterior chest radiograph; severe hypoxaemia (arterial oxygen tension/inspiratory oxygen fraction ratio $\left(\mathrm{Pa}_{\mathrm{a}} \mathrm{O}_{2}\right)$ $\left.F_{\mathrm{I}, \mathrm{O}_{2}}\right)<200$ ); mean PCWP $<12 \mathrm{mmHg}$; and no clinical evidence of heart failure [12].

As control samples, 10 aspirated secretions were obtained from 10 intubated patients with other pulmonary diseases, who received mechanical ventilation and showed no evidence of left congestive heart failure ( 2 females and 8 males, aged 62 \pm 4 yrs (range 30-74 yrs); their diseases included pulmonary emphysema (3), chronic obstructive pulmonary disease (2), bronchial asthma (2) and pulmonary fibrosis (3). As a further control, 20 sputum (mucoid and mucopurulent) samples were collected on different mornings from 10 nonintubated patients with various pulmonary diseases ( 6 females and 4 males, aged $56 \pm 5$ yrs (range $26 \pm 73$ yrs): their diseases included chronic bronchitis (3), bronchial asthma (4), chronic obstructive pulmonary disease (1), pneumonia (1), and pulmonary emphysema (1).

The total of 122 samples of sputum and aspirated airway secretions were all collected in the morning (08:0009:00 h), except on the first day of ICU admission, and were used for the determination of SP-A concentration as described below. On the first day of ICU administration, samples were collected within $1 \mathrm{~h}$ of PCWP measurement.

\section{SP-A measurement}

A mixture of $0.5 \mathrm{~mL}$ of the sample and $2 \mathrm{~mL}$ of 0.01 $\mathrm{M}$ Tris-HCl buffer (pH 7.4), containing $1 \mathrm{mM}$ ethylenediamine tetra-acetic acid (EDTA), was homogenized for $1 \mathrm{~min}$ in an ice-cold bath by means of an ultra-disperser (Model-LK-21; Yamato Co., Tokyo). The homogenate was diluted with $0.6 \%$ sodium dodecyl sulphate (SDS) and 2\% Triton X-100 to separate SP-A from lung surfactant phospholipids, and centrifuged at $10,000 \times \mathrm{g}$ for 10 min at $4^{\circ} \mathrm{C}$. The SP-A content of the supernatant was measured using an enzyme-linked immunoassay (ELISA) kit which was provided by K. Hosoda (Teijin Institute of Bio-Medicine, Tokyo, Japan) [6, 7]. Aliquots $(200 \mu \mathrm{L})$ of SP-A standards or 1:10 dilutions of the supernatant from sputum samples in buffer solution I ( $0.6 \%$ SDS $/ 2 \%$ Triton X-100/0.01 M phosphate-buffered saline (PBS), $\mathrm{pH}$ 7.2) (final dilution 1:500) and $200 \mu \mathrm{L}$ of peroxidaselabelled monoclonal antibody PE10 $\left(5 \mu \mathrm{g} \cdot \mathrm{mL}^{-1}\right)$ were mixed thoroughly. The peroxidase-labelled PE10 (50 $\mu \mathrm{g}$ protein) was dissolved in $10 \mathrm{~mL}$ of a buffer solution II (0.25\% skimmed milk/0.01 M PBS, pH 7.2).

A plastic bead coated with monoclonal antibody PC6 was added to each test tube containing the above mixture. The test tube was then incubated at $37^{\circ} \mathrm{C}$ for 90 $\mathrm{min}$. After incubation, the reaction mixture was removed by suctioning with an aspirator and the bead was washed three times with $3 \mathrm{~mL}$ of distilled water. Four hundred microlitres of a mixture of substrate solution and devel- 
oper were added to each tube. The substrate solution (5 $\mathrm{mM} \mathrm{H} \mathrm{O}_{2} / 0.1 \mathrm{M}$ phosphate-citrate buffer, $\mathrm{pH} 4.0$ ) was mixed with the developer $(0.06 \%$ tetramethylbenzidine $\mathrm{HCl}, \mathrm{pH} 2.0$ ) just before use. The tube was then incubated at $37^{\circ} \mathrm{C}$ for $30 \mathrm{~min}$. The reaction was stopped by the addition of $1 \mathrm{~mL}$ of $0.5 \mathrm{M} \mathrm{H}_{2} \mathrm{SO}_{4}$.

The absorbency of each tube was measured at $450 \mathrm{~nm}$ using a spectrophotometer (Hitachi 200A; Hitachi Co., Tokyo). SP-A purified from full-term human amniotic fluid was used as a standard, and $1.2 \mu \mathrm{g}$ of SP-A was lyophilized with $0.5 \%$ bovine serum albumin/0.01 M PBS, $\mathrm{pH}$ 7.2. The lyophilized material was dissolved in $2 \mathrm{~mL}$ of buffer solution I and diluted into $0,10,100,500,1,000$, $2,000,3,000$ and $4,000 \mathrm{ng} \cdot \mathrm{mL}^{-1}$ of SP-A to produce a calibration curve. This assay was capable of measuring from 2.5 to $4,000 \mathrm{ng}$ of SP-A. All assays were performed in duplicate, and data were expressed as mean values.

\section{Measurement of PCWP}

The PCWP was measured directly in a steady state, with the patient in the supine position, using a 7.5French single-lumen balloon-tipped catheter (Boxter Healthcare Co., Irvine, CA, USA) and disposable transducers (A BOC Health Care Co., Viggo-Spectramed (S) Pte Ltd, Singapore) levelled to the mid-axillary line. The pulmonary-wedge position was confirmed in the catheter laboratory by direct fluoroscopic observation of the catheter tip and by the appearance of a typical wedge-pressure tracing. Except for the first day of ICU admission, PCWP was measured in the morning (08:0009:00 $\mathrm{h}$ ) and used for the data analysis. On the first day of ICU admission, PCWP was measured within $1 \mathrm{~h}$ of aspirated secretion and sputum collection.

Data are expressed as mean \pm sE. For mean comparisons, Student's two-tailed unpaired t-test was used for statistical analysis, and the Cochran Cox t-test was used when Bartlett's test for uniformity of variance showed it to be nonuniform. The regression coefficient was also used for statistical analysis. Significance was accepted at a p-value of less than 0.05 .

\section{Results}

SP-A concentrations in aspirated secretion and sputum from the patients with cardiogenic pulmonary oedema
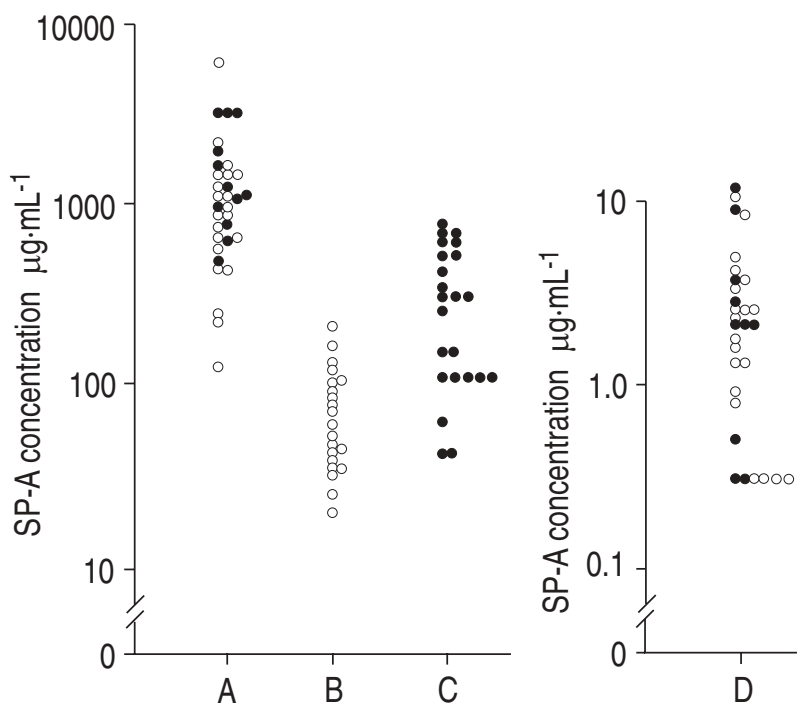

Fig. 1. - Surfactant apoprotein A (SP-A) concentrations in aspirated secretions $(\bullet)$ and sputum $(O)$ from: cardiogenic pulmonary oedema patients with elevated mean pulmonary capillary wedge pressure (PCWP) ( $\geq 12 \mathrm{mmHg} ; \mathrm{n}=33$ ) (A); clinically stable congestive heart failure patients $(n=21)(B)$; adult respiratory distress syndrome (ARDS) patients $(n=23)(C)$; and control patients with other respiratory diseases $(n=30)(D)$. There was no significant difference between aspirated secretion and sputum samples. SP-A concentrations in cardiogenic pulmonary oedema were significantly higher than those in congestive heart failure, ARDS and control patients (all $\mathrm{p}<0.001$ ). SP-A concentration both in congestive heart failure and ARDS patients were also significantly higher than those in control patents (both $\mathrm{p}<0.01$ ). See table 2 for detail.

with elevated PCWP (mean PCWP $>12 \mathrm{mmHg}$ ), clinically stable congestive heart failure, ARDS, and other pulmonary diseases (controls) are shown in table 2 and figure 1. Among the 48 samples of aspirate and sputum from patients with cardiogenic pulmonary oedema used for the SP-A measurement, nine samples lacked PCWP values and six samples were associated with low PCWP values (mean PCWP $<12 \mathrm{mmHg}$ ). SP-A concentrations from control patients were mean 3.0 (range 0.3-1.1) $\mu \mathrm{g} \cdot \mathrm{mL}^{-1}$. The three other groups all showed significantly higher values than the control patients, without any overlap of ranges (table 2 and fig. 1).

Three patients with cardiogenic pulmonary oedema (two acute myocardial infarction patients and one dilated cardiomyopathy patient; patients No. 4, 6 and 8) (table 1) did not respond to intensive care and died of resulting heart and respiratory failure (not arrhythmias) 2-4

Table 2. - Surfactant apoprotein A (SP-A) concentrations in aspirated airway secretion and sputum

\begin{tabular}{lccc}
\hline & $\mathrm{Pt}$ & \multicolumn{2}{c}{$\mathrm{SP}-\mathrm{A} \mu \mathrm{g} \cdot \mathrm{m}^{\mathrm{L}-1}$} \\
\cline { 2 - 4 } & $\mathrm{n}$ & Mean $\pm \mathrm{SE}$ & Range \\
\hline Cardiogenic pulmonary oedema & & & \\
with mean PCWP $>12 \mathrm{mmHg}$ & 33 & $1324 \pm 197$ & $125-5875^{*}$ \\
$\quad$ Aspirated airway secretion & 12 & $1612 \pm 289$ & $630-3350^{*}$ \\
Sputum & 21 & $1160 \pm 260$ & $125-5875$ \\
Clinically stable congestive heart failure (all sputum samples) & 21 & $78 \pm 10$ & $20-206^{+}$ \\
Adult respiratory distress syndrome (ARDS) (all aspirated secretion) & 23 & $311 \pm 47$ & $102-750^{+}$ \\
Controls with other pulmonary diseases & 30 & $3.0 \pm 0.6$ & $0.3-11$ \\
$\quad$ Aspirated airway secretion & 10 & $3.1 \pm 1.1$ & $0.3-11$ \\
Sputum & 20 & $2.7 \pm 0.6$ & $1.3-11$ \\
\hline
\end{tabular}

PCWP: pulmonary capillary wedge pressure; Pt: patients. *: $\mathrm{p}<0.001$, compared to stable congestive heart failure, ARDS and controls; ${ }^{+}$p $<0.001$, compared to controls. 


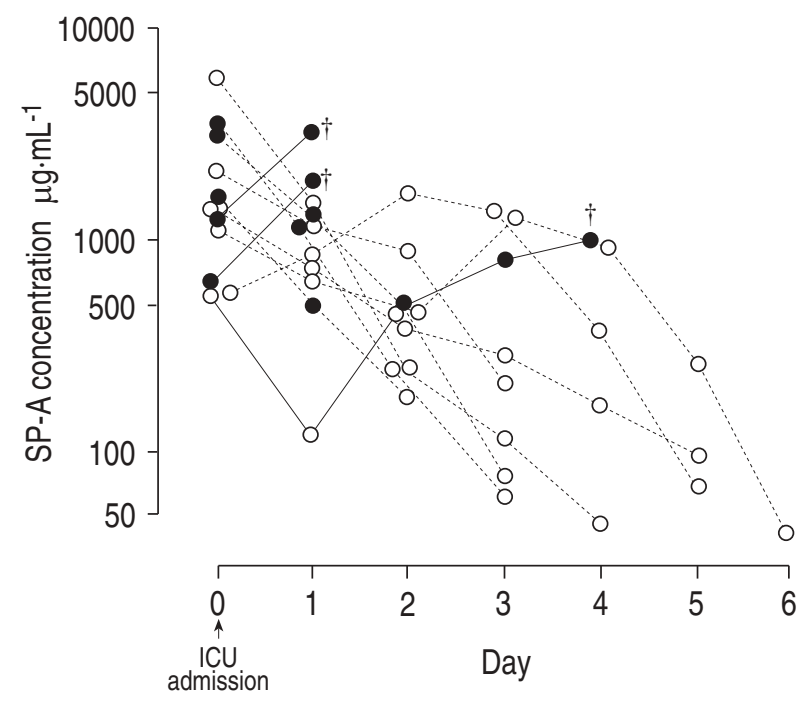

Fig. 2. - Time course of surfactant apoprotein A (SP-A) concentrations in aspirated airway secretion $(\bullet)$ and sputum $(O)$ from 11 cardiogenic pulmonary oedema patients after intensive care unit (ICU) admission. Three patients died of respiratory and heart failure $(\dagger$, solid lines), having shown a rapid increase in SP-A concentrations before death. The other patients improved clinically and left the ICU within 8 days, showing a decrease in SP-A concentrations.

days after ICU admission. They all showed an increase in the SP-A concentration before death, as shown in figure 2. The other eight patients showed clinical improvement and left the ICU within 8 days, with a decreased SP-A concentration (fig. 2). Thus, SP-A concentrations in aspirated secretion and sputum samples correlated with their clinical course and laboratory data, with no significant differences between aspirated secretion and sputum $(n=48)$.

Nine sputum samples lacked PCWP values because these samples were obtained when the patients had improved clinically and, therefore, had not received the PCWP measurement. Mean PCWP values in cardiogenic pulmonary oedema patients correlated significantly with SP-A concentrations, expressed logarithmically, in aspirated secretion $(\mathrm{r}=0.77 ; \mathrm{p}<0.01 ; \mathrm{n}=13)$, sputum $(\mathrm{r}=0.78 ; \mathrm{p}<$ $-0.001 ; n=26)$ and both $(r=0.78 ; p<0.001 ; n=39)$ as shown in figure 3. Although the levels of SP-A in sputum tended to be lower than those in aspirates, this difference was not statistically significant (table 2 and fig. 1). As shown in table 2 and figure 1, SP-A concentration in samples of aspirated secretion and sputum from cardiogenic pulmonary oedema patients with elevated mean PCWP $(\geq 12$ mmHg; $n=33$ ) showed a 100-2,000-fold higher value than did sputum samples from control patients with various other pulmonary diseases. Sputum samples from patients with clinically stable congestive heart failure showed a much lower SP-A concentration than those from cardiogenic pulmonary oedema patients, but were still significantly higher than those from control patients, without any overlap of ranges (table 2 and fig. 1).

ARDS patients all received tracheal intubation with mechanical ventilation and, with the exception of one patient, died of respiratory failure, septic shock and multiple organ failure within 6-12 days of ICU admission, despite intensive care, including a pulse therapy of methylprednisolone. One patient (patient No. 21 in table 1) was successfully treated and left the ICU 6 days after

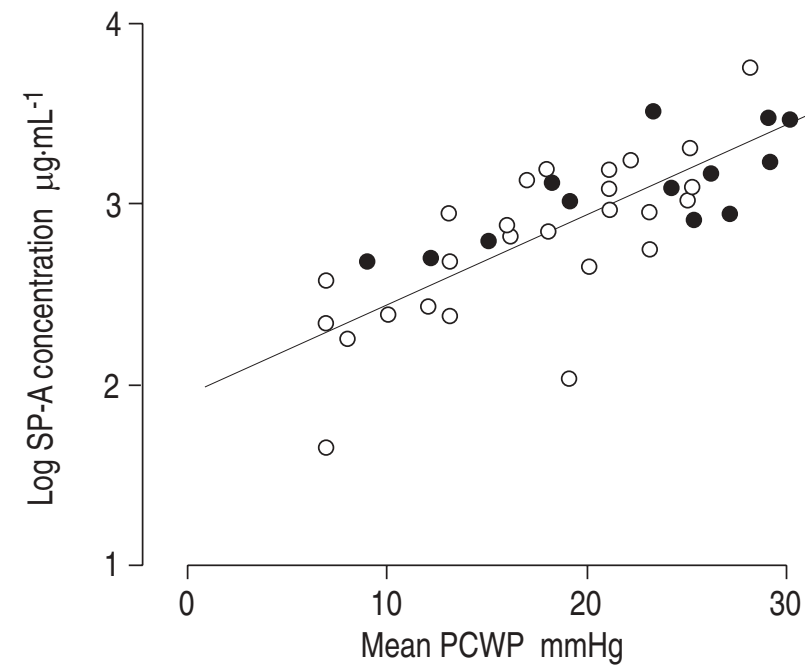

Fig. 3. - Relationship between surfactant apoprotein A (SP-A) concentrations and mean pulmonary capillary wedge pressures (PCWPs) in cardiogenic pulmonary oedema patients. Mean PCWPs correlated significantly with SP-A concentrations in aspirated secretion $(\bullet ; n=13)$ and sputum $(\mathrm{O} ; \mathrm{n}=26)$ expressed by logarithm $(\mathrm{r}=0.78 ; \mathrm{p}<0.001 ; \mathrm{n}=39)$.

admission. SP-A concentrations in aspirated secretions from ARDS patients showed an intermediate value between those from cardiogenic oedema patients and those from control patients, and were significantly lower than those from cardiogenic pulmonary oedema patients, as shown in table 2 and figure 2 . However, SP-A concentrations from ARDS patients did not correlate significantly with any clinical features, including chest radiographic findings, degree of hypoxaemia $\left(\mathrm{Pa}_{\mathrm{a}, \mathrm{O}_{2}} / \mathrm{F}_{\mathrm{I}}, \mathrm{O}_{2}\right)$ or mean PCWP values.

\section{Discussion}

This study showed that SP-A concentrations in airway secretions were higher in patients with cardiogenic pulmonary oedema. SP-A concentrations in ARDS and stable congestive heart failure were lower, but were still significantly higher than in control patients, and showed no overlap with control values.

Airway secretions in pulmonary oedema are often contaminated with blood (or plasma) but the serum SP-A concentration is $\leq 1 \mu \mathrm{g} \cdot \mathrm{mL}^{-1}$ [13]. Since serum from the same patients showed $1 / 200$ to $1 / 3,000$ or lower SP-A concentrations than the sputum, contamination by blood or serum would have little effect on the alterations in the SP-A concentrations that were observed in the sputum samples. Furthermore, contamination with saliva is usually present when collecting sputum samples for chemical analysis. Similarly, contaminating saliva would not substantially dilute the expectorated SP-A, since saliva shows a much lower concentration [8]. In fact, there was no significant difference in SP-A concentration between the sputum and aspirated secretion.

In general, cardiogenic or hydrostatic pulmonary oedema occurs abruptly and alveolar flooding washes out alveolar surfactant into the airways in the same manner as bronchoalveolar lavage, resulting in a large amount of foamy sputum. Consistent with this is our finding of higher (400 fold or more) values of SP-A in samples 
aspirated of secretion and sputum from the patients with cardiogenic pulmonary oedema compared to those from control patients. Furthermore, the SP-A concentrations correlated significantly with the mean PCWP values, returned to lower levels when cardiogenic pulmonary oedema was successfully treated, and increased when the treatment was not effective. These findings indicate that determination of the SP-A concentration both in aspirated secretion and sputum may be useful for detecting and monitoring cardiogenic pulmonary oedema.

The present immunoassay using the ELISA kit requires a sample of just $0.5 \mathrm{~mL}$. The patients with cardiogenic pulmonary oedema could expectorate $0.5 \mathrm{~mL}$ or more of sputum before tracheal intubation and even after the removal of the tracheal tube. The present method using an ELISA kit represents an improved immunoassay for the determination of SP-A, which simplifies the two-site simultaneous immunoassay with monoclonal antibodies against SP-A described by KUROKI et al. [4]. The present assay kit makes it possible to complete many samples in 50 min using a common spectrometer [6, 7], and could be used routinely in a clinical laboratory for SP-A determination in samples of airway secretions or sputum, in addition to the other diagnostic tools for cardiogenic pulmonary oedema.

In successfully-treated patients with cardiogenic pulmonary oedema, the markedly elevated SP-A concentrations returned to lower levels of $10-100 \mu \mathrm{g} \cdot \mathrm{mL}^{-1} 3-6$ days after ICU admission, as the PCWP values also returned to within normal limits. However, in this condition, the SP-A values were still significantly higher than those of control patients. To determine whether the higher SP-A concentration with normal PCWP value resulted from congestive heart failure or delayed SP-A clearance from alveolar regions, we examined the SPA concentration in sputum samples from clinically stable congestive heart failure patients, who had not shown any acute pulmonary oedema for 3 months or more and who also showed normal PCWP values. These patients also showed significantly higher values of SP-A concentration in the sputum samples compared to the control patients. It has been shown, even at the so called "interstitial oedema" stage, that the capillary endothelial intercellular junctions are widened, allowing passage of macromolecules $[14,15]$. This suggests that SP-A measurement could be used to detect congestive heart failure even when the PCWP is within the normal range.

A noninvasive method or tool for the detection of pulmonary oedema could contribute to the early detection of congestive heart failure. With powerful diuretics and/ or digitalis, patients with chronic severe but stable heart failure can now be managed as out-patients or in hospitals where catheterization facilities for estimation of cardiac function are limited. Such patients often have pulmonary oedema after a common cold, viral infection, bronchitis or pneumonia, and it is sometimes difficult to distinguish this condition from pneumonia by chest radiography alone, as was shown in the case of another patient with cardiogenic pulmonary oedema [16]. Although PCWP is an important indicator of cardiac function, it is an invasive procedure and occasionally causes serious complications [11]. The measurement of SP-A concentrations in airway secretions is easy and, thus, useful for the detection of cardiogenic pulmonary oedema prior to catheterization, and could be put into routine clinical use since ELISA kits are now available commercially.

The increase in SP-A concentrations in sputum and airway secretion does not seem to be specific to cardiogenic pulmonary oedema but also occurs in other types of pulmonary oedema, including noncardiogenic pulmonary oedema, i.e. ARDS. We found significantly higher values of SP-A in the aspirated secretion from ARDS patients compared to those from control patients. However, these SP-A concentrations failed to correlate with any clinical features and parameters of ARDS. We found normal PCWP values in all ARDS patients studied within $24 \mathrm{~h}$ of the onset of ARDS, consistent with noncardiogenic pulmonary oedema due to increased vascular permeability. However, elevated mean PCWPs (range 13-17 $\mathrm{mmHg}$ ) developed in two of the ARDS patients beyond this period, suggesting an additional role of cardiogenic or hydrostatic pulmonary oedema in ARDS.

Airway secretion and sputum samples from ARDS patients showed smaller SP-A concentrations than those from cardiogenic pulmonary oedema patients, in spite of the fact that ARDS is known to be "permeability oedema". ARDS patients do not expectorate such large amounts of foamy sputum as seen in cardiogenic pulmonary oedema patients, resulting in a much smaller level of SP-A in the airway tracts. Furthermore, alveolar fluids from ARDS patients contain a much higher amount of plasma proteins than those from cardiogenic pulmonary oedema patients [17]. Plasma proteins and bacterial infections inactivate and reduce pulmonary surfactant or SP-A [18, 19]. An impairment of surfactant function is known to exist in ARDS [20], and the measurement of SP-A in bronchoalveolar fluid samples from ARDS patients also demonstrated a decline of the surfactant apoprotein in the alveoli [21]. A recent study by DoyLE et al. [22] (published during the preparation of this manuscript) reported that the serum SP-A concentration of ARDS patients was higher than that of cardiogenic pulmonary oedema patients because of alveolocapillary membrane injury. Surfactant apoprotein production is deficient in ARDS, presumably resulting from damage to type II alveolar epithelial cells. Furthermore, the ARDS patients in the present study received glucocorticoids, that are known to affect surfactant production and secretion [23]. These may be possible explanations for the absence of a significant relationship between the SP-A concentration and the clinical features of ARDS, and also for the decreased SP-A concentrations in the samples of aspirated secretion and sputum samples from ARDS patients compared to those from patients with cardiogenic pulmonary oedema. Furthermore, it is possible that patients with cardiac oedema develop surfactant deficiency associated with alveolar epithelial damage as the injury progresses. Thus, the potential problems of the present method may include false-negative results.

In conclusion, the measurement of the surfactant apoprotein A concentration in airway secretion (both aspirated and expectorated) is useful for the detection of cardiogenic pulmonary oedema, since the level of surfactant apoprotein A correlated significantly with the level of pulmonary capillary wedge pressure. Furthermore, although not conclusive because of the lack of an appropriate objective indicator, this is also a possible 
tool for the detection of noncardiogenic oedema or adult respiratory distress syndrome. Thus, measurement of surfactant apoprotein A in airway secretions might help to distinguish pulmonary oedema from other disorders which show severe pulmonary symptoms.

Acknowledgements: The authors gratefully acknowledge S. Matsukawa and all other staff in ICU for helpful suggestions, and . B. Bell for reading the manuscript.

\section{References}

1. King RJ, Clements JA. Surface active materials from dog lung. II. Composition and physiological correlations. Am J Physiol 1972; 223: 715-726.

2. Young SL, Wright JR, Clements JA. Cellular uptake and processing of surfactant lipids and apoproteins SPA by rat lung. $J$ Appl Physiol 1989; 66: 1336-1342.

3. Kuroki Y, Fukuda Y, Takahashi H, Akino T. Monoclonal antibodies against human pulmonary surfactant apoproteins: specificity and application in immunoassay. Biochim Biophys Acta 1985; 836: 201-209.

4. Kuroki Y, Takahashi H, Fukada Y, et al. Two-site "simultaneous immunoassay" with monoclonal antibodies for the determination of surfactant apoproteins in human amniotic fluid. Pediatr Res 1985; 19: 1017-1020.

5. Snyder JM, Kwun JE, O'Brien JA, Rosenfeld CR, Odom MJ. The concentration of the $35 \mathrm{kDa}$ surfactant apoprotein in amniotic fluid from normal and diabetic pregnancies. Pediatr Res 1988; 24: 728-734.

6. Akino T, Shimizu H, Mizumoto M, et al. Simplified monoclonal immunoassay for pulmonary surfactant 35 $\mathrm{kDa}$ apoprotein in human amniotic fluid. Clin Chem 1989; 34: 1513.

7. Shimizu H, Hosoda K, Mizumoto M, et al. Improved immunoassay for the determination of surfactant protein A (SP-A) in human amniotic fluid. Tohoku J Exp Med 1989; 157: 269-278.

8. Masuda T, Shimura S, Sasaki H, Takishima T. Surfactant apoprotein A concentration in sputum for diagnosis of pulmonary proteinosis. Lancet 1991; 337: 580-582.

9. Chakko S, Woska D, Martienz H, et al. Clinical, radiographic and hemodynamic correlations in chronic congestive heart failure: conflicting results may lead to inappropriate care. Am J Med 1991; 90: 353-359.

10. Swan HJC, Ganz W, Forrester J, Marcus H, Diamond $\mathrm{G}$, Chonette D. Catheterization of the heart in man with use of a flow-directed balloon-tipped catheter. $N$ Engl J Med 1970; 283: 447-451.

11. Mermel LA, Maki DG. Infectious complications of SwanGanz pulmonary artery catheters: pathogensis, epidemiology, prevention, and management. Am J Respir Crit Care Med 1994; 149: 1020-1036.

12. Fowler A, Hamman R, Zerbe G, Benson K, Hyers T. Adult respiratory distress syndrome: prognosis after onset. Am Rev Respir Dis 1985; 132: 472-478.

13. Kuroki Y, Tsutahara S, Shijubo N, et al. Elevated levels of lung surfactant protein A in sera from patients with pulmonary fibrosis and pulmonary alveolar proteinosis. Am Rev Respir Dis 1993; 147: 723-729.

14. Crapo JD. New concepts in the formation of pulmonary edema. Am Rev Respir Dis 1993; 147: 790-792.

15. Bachofen H, Schürch S, Weibel ER. Experimental hydrostatic pulmonary edema in rabbit lungs: barrier lesions. Am Rev Respir Dis 1994; 147: 997-1004.

16. Masuda T, Shimura S, Takishima T. Surfactant apoprotein A in airway secretions in pulmonary oedema (Letter). Lancet 1991; 338: 1396-1397.

17. Hasegawa N, Husari AW, Hart WT, Kandra TG, Raffin TA. Role of the coagulation system in ARDS. Chest 1994; 105: 268-277.

18. Holm BA, Venkitaraman AR, Enhorning G, Notter RH. Biophysical inhibition of synthetic lung surfactants. Chem Phys Lipids 1990; 52: 243-250.

19. Baughman RP, Sternberg RI, Hull W, Buchsbaum JA, Whitsett J. Decreased surfactant protein A in patients with bacterial pneumonia. Am Rev Respir Dis 1993; 147: 653-657.

20. Gregory TJ, Longmore WJ, Moxley MA, et al. Surfactant chemical composition and biophysical activity in adult respiratory distress syndrome. J Clin Invest 1991; 88: 1976-1981.

21. Pison U, Obertacke U, Seeger W, Hawgood S. Surfactant protein A (SP-A) is decreased in acute parenchymal lung injuries associated with polytrauma. Eur J Clin Invest 1992; 22: 712-728.

22. Doyle IR, Nicholas TE, Bersten AD. Serum surfactant protein-A levels in patients with acute cardiogenic pulmonary edema and adult respiratory distress syndrome. Am J Respir Crit Care Med 1995; 152: 307-317.

23. Batenburg JJ, Elfring RH. Pretranslational regulation by glucocorticoid of fatty acid and phosphatidylcholine synthesis in type II cells from fetal rat lung. FEBS Lett 1992; 307: 164-168. 